\title{
事 ADVISOR REVEWS-STANDARD REVEW
}

doi:10.5260/chara.14.4.33

Date of Review: February 2013

Composite Score:

$\star \star \star \star 1 / 4$

\author{
Reviewed by: Elsabé Olivier \\ Department of Library Services \\ <elsabe.olivier@up.ac.za> \\ Prof Ina Fourie \\ Department of Information Science \\ <ina.fourie@up.ac.za> \\ University of Pretoria \\ Private Bag X20 \\ Hatfield, Pretoria \\ South Africa, 0028
}

Disclosure: The University of Pretoria is indicated as a shareholder of Sabinet. This dates back to the time (30 years ago) when Sabinet was formed by 45 academic and research institutions as a non- profit company. When it moved to a commercial company all "founding members" of the not-for-profit company became shareholders in the current structure. There is, however, no financial gain for the University of Pretoria.

\section{Abstract \\ This review critically examines the African Electronic Journals (SA ePublications) database which was developed by Sabinet $<\mathrm{http} / / /$ www.sabinet.co.za> with the intention to provide easy access to full- text articles published in South Africa as well as southern Africa. Sa- binet has been in operation since 1983, running as a non-profit or- ganisation for the first 17 years. Sabinet is an aggregator of premier southern African electronic publications serving a diverse client base which includes libraries, research organisations, law firms and in- dividual subscriptions. Apart from African Electronic Journals (SA ePublications), Sabinet also provides access to South African Union Catalog (SACat), the South African National Bibliography (SANB), Index to South African Periodicals (ISAP), the Union Catalogue for Theses and Dissertations (UCTD) and African Digital Repository, amongst others. Information on the other databases available through Sabinet can be found on the Sabinet Web site. African Electronic Journals (SA ePublications)'s major strength lies in the fact that it is the only database that provides convenient, organised access to a collection of full-text journal articles from a specific geographic area that is not covered as extensively by other international databases.}

African Electronic Journals (SA ePublications) consists of a full collection of more than 300 journal titles and more than 120,000 full-text articles. Tables of content of all the journals are also available. To streamline access and to allow for individual needs, the database content is grouped into seven subject collections: Business and Finance, Law, Medical and Health, Religion, Science, Technology and Agriculture, and Social Science and Humanities.

African Electronic Journals (SA ePublications) certainly meets with its claim to be the most comprehensive database in the world on fulltext electronic journals published in South Africa as well as southern Africa. Apart from being an essential source of information for any researcher from southern Africa, it is also an essential resource for any research related to southern Africa.

\section{Pricing Options}

Sabinet does not mention any pricing options for African Electronic Journals (SA ePublications) on their Web site; clients are referred to $<$ info@sabinet.co.za> for a quotation and information on pricing options. Following our enquiry it was explained that pricing works on an annual subscription basis. The price of journal titles is determined by the publishers of the journals. As new titles are added to the database the database price will increase. The same applies to the individual collections. Pricing options are very flexible. Clients can (1) subscribe to the full collection of journal titles, (2) choose one or more of the seven subject collections, or (3) subscribe to individual journal titles. An option for non-subscribers to purchase single articles using their credit cards is also available <http://www.sabinet.co.za/onceoffdoc/>.

The pricing for subject collections starts from $\$ 680$ and the price for individual titles amounts to $\$ 55$. No special or consortial discount is applicable to institutions.

Pricing options are approached from the subscriber or client's point of view, as well as from the point of view of journal publishers who want to participate in making their full-text journal articles available through African Electronic Journals (SA ePublications). For publishers who wish to include their journal titles in African Electronic Journals (SA ePublications) there are no initial costs and additionally they are compensated on an annual basis by Sabinet. Payment amounts to a percentage of the subscription price set by the publisher. For example if a collection consists of 25 journals then the price for that collection will be the sum of the 25 individually set prices. Subscribers can also select individual journals and the same formula will apply. At the end of the financial year after an external audit was done, an amount is paid over to publishers according to the number of subscriptions to the specific title.

Although users are expected to complete a basic registration form if they are not subscribed to African Electronic Journals (SA ePublications), anyone can search the Open Access collection. In addition metadata and abstracts for all articles included in the full African 
Electronic Journals (SA ePublications) can be searched by non-subscribers. Only subscribers, however, have access to the full-text articles.

\section{Product Description}

African Electronic Journals (SA ePublications) is available from Sabinet <http://www.sabinet.co.za $>$ through a single platform $<$ http:// reference.sabinet.co.za/>. With right, it claims to be the most comprehensive database in the world providing easy access to full-text journal articles published in South Africa and southern Africa. It was launched in 2001 with two journal titles: South African Journal of Chemistry and South African Journal of Wildlife Research. New journal titles are added on an on-going basis. Sabinet also seems to be committed to on-going improvements such as the new user interface introduced in May 2012, free training (on request) for subscribers to its products, subscription to discussion lists, and options for personalisation (MySabinet). Subscription to African Electronic Journals (SA ePublications) provides access to older, retrospective full-text journal articles, as well as the latest information by means of an alerting service.

\section{CONTENT PROVIDED}

African Electronic Journals (SA ePublications) consists of a collection of more than 300 journal titles and more than 120,000 full-text articles by publishers from South Africa as well as other southern African countries. It covers research reported in journals from these countries; although most of such research is done in Africa, the database also includes work that has been done elsewhere reported in a journal published in African Electronic Journals (SA ePublications). New journal titles are added on an on-going basis.

Since the main criterion for inclusion in African Electronic Journals (SA ePublications) is the country where the journal is published, namely South Africa or a country from southern Africa, the database does not have a specific topic focus. The wide variety of topics covered is reflected in the collections into which the journals are grouped: Business and Finance, Law, Medical and Health, Religion, Science, Technology and Agriculture, and Social Sciences and Humanities.

Database items include an abstract, and the full-text which is available in PDF format; the full-text is searchable. Tables of contents of full-text articles and abstracts are also available as part of an alerting service. Apart from the latest issue for individual journal titles, older issues available are also indicated in the database and go as far back as 2000 (some even earlier). Older issues of African journals are also available through another Sabinet database, African Journal Archive $<$ http://www.sabinet.co.za/african-journal-archive/>.

As can be expected, some journal titles also appear in other databases such as South African Journal for Research in Sport, Physical Education and Recreation (also available in SPORTDiscus), South African Journal of Business Management (also available in Business Source Premier and MasterFile Premier), and South African Journal of Philosophy/Suid-Afrikaanse Tydskrif vir Wysbegeerte (also available in Academic Search Premier and Humanities International). However, African Electronic Journals (SA ePublications) remains the most comprehensive single database on South African and southern African content with the added advantage that all the articles are available in full-text and available without any embargoes. Although the metadata of articles is searchable by anyone, subscription is required should you wish to view the full-text of an article. Exceptions to this rule are the Open Access journals.

\section{INTENDED AUDIENCE}

Subscribers to African Electronic Journals (SA ePublications) include academic, public, government, legal and corporate libraries, research organisations, law firms, public and private organizations, and individual subscribers. The content caters to full-text for the serious researcher such as covered in South African Journal of Science which is also indexed in Thomson Reuters, as well as journals that cover more popular topics or topics with a practical slant such as Veld \& Flora.

Research on Africa is often conducted from non-African countries or from grant research holders in these countries working with African partners. Since African Electronic Journals (SA ePublications) includes a unique collection of full-text articles that is not always included in other databases, this database can be considered an essential source for anybody doing research related to Africa.

\section{SCOPE}

The scope of African Electronic Journals (SA ePublications) is demarcated by two requirements: (1) availability of articles in electronic format; (2) the origin of the journal publisher as South African or from a southern African country. Although journals from South Africa are dominant, publishers based in Botswana, Ghana, Namibia, and Nigeria are also included. Journals from southern African countries that are published by international publishers such as Elsevier, Routledge, or Wiley-Blackwell are not included. Journal titles are included through various means: (1) Sabinet approaches publishers by following on leads of publishers; (2) publishers approach Sabinet - there is a growing trend in this; (3) clients suggest publishers to be approached. The wide spectrum of topics covered has been noted under the discussion of Content.

An A-Z list of journal titles included in African Electronic Journals (SA ePublications) is provided on their Web site $<\mathrm{http}: / /$ reference. sabinet.co.za/sa_epublications_a_z>. The list includes the journal name, the ISSN-Print, the E-ISSN (where applicable), frequency of publication (e.g., tri-annually, annually), language of publication, accreditation source (e.g., DOE acronym for the South African Department of Education), and whether the journal is active, discontinued, or whether the access is restricted. Restricted access applies to journals that have changed from a local publisher to a publisher with whom the original publisher signed an exclusive agreement (usually international publishers). These journals' contents are then no longer added to Sabinet and access can only be given to clients who subscribed to them in the past. These titles are also removed from the price list and will not be sold to new subscribers.

\section{NEED FOR SPECIAL INSTALLATION REQUIREMENTS:}

No special installation requirements such as plug-ins or special software apply to access African Electronic Journals (SA ePublications). Clients only require an up-to-date browser and Adobe Acrobat to view the full text of the articles. At the time of this review the recommended browsers were Mozilla FireFox 11.0, Internet Explorer (IE 7+) and Google Chrome.

\section{Critical Evaluation STRENGTHS}

The main strength of African Electronic Journals (SA ePublications) lies in the easy and convenient access to a wide collection of journal titles published in electronic format by publishers in a geographically demarcated area - South Africa and other southern African countries. 


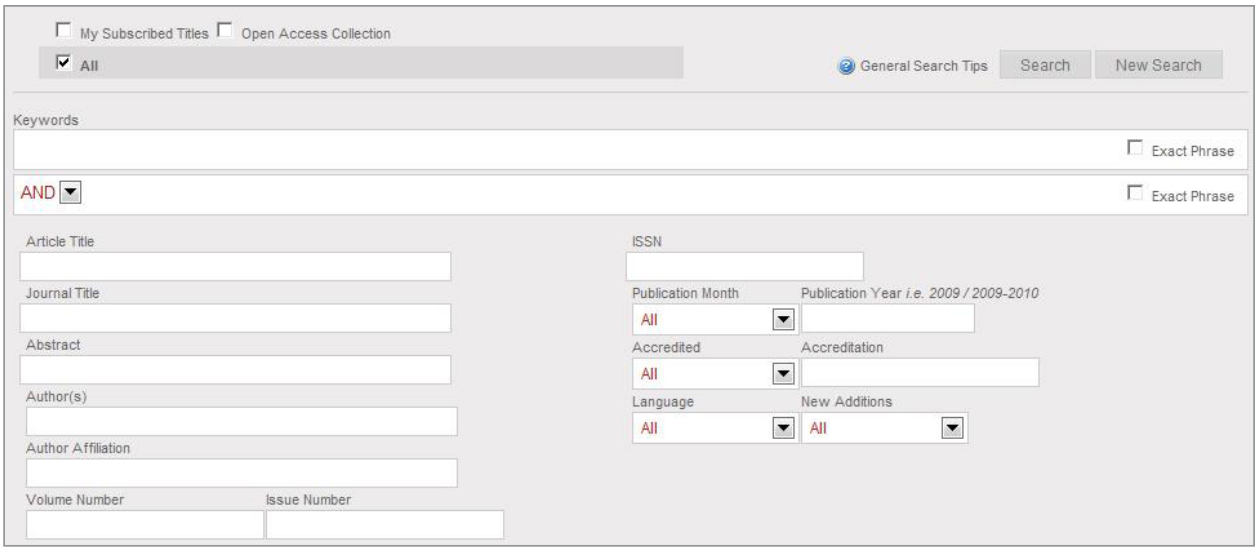

FIGURE 1 Search interface

Journal of Public Administration, Without Prejudice (a law journal), South African Journal of Higher Education, South African Journal of Psychology, and Obstetrics and Gynaecology Forum to mention but a few.

\section{USER INTERFACE}

African Electronic Journals (SA ePublications) introduced a new, improved user interface in May 2012. The search

Although some of the journal titles might be included in other databases with full-text access, none of these offers such clear geographic demarcation. There is good evidence of on-going expansion based on interest from publishers to participate, initiatives from Sabinet and recommendations by clients. Commitment to comprehensive and specific information retrieval according to the needs of clients is shown in the latest version of the user interface, and especially the faceted filters that can streamline search strategies.

\section{WEAKNESSES}

One of the identified weaknesses is that the button Add All To Action List is hidden at the bottom of the page. The reviewers also found the My Action List link difficult to spot on the page - it is right at the bottom of the screen in a dark grey box. If clients want to print or e-mail one or more of the results, these items need to be added to the Action List first. Although experienced database clients will probably logically deduct that this procedure should be followed, novice clients might be at a loss initially and will have to consult the How do the results work link.

The results screens also contain much information and detail in the right hand column and this might be interpreted as too busy for some clients. Only 10 items can be viewed at a time and it would have been useful to increase this number so that clients need to view fewer pages.

\section{CONTENT}

A very wide selection of topics is covered, and access to the content is streamlined through categorisation in broad subject collections. Although journal titles from South African publishers dominate, there is also coverage of journal titles from other southern African countries such as Botswana, Ghana, Namibia, and Nigeria. African Electronic Journals (SA ePublications) is currently an essential resource for any research done on South Africa, but there is good evidence that by increasing the number of publishers and journal titles from other southern African countries, it can become an essential resource for research on these geographic areas as well.

A wide spectrum of reputable journals on a variety of subjects can be accessed via African Electronic Journals (SA ePublications) such as interface is depicted in Figure 1. Overall the look and feel of the interface is even more user-friendly and functional towards the novice as well as expert searcher. It supports navigation, searching, and the display of results.

At the top of the screen there is an option to either search only the client's own subscribed titles, the Open Access collection, or the complete database. The default is All if a client subscribes to more than 100 journal titles; otherwise the default is My Subscribed Titles. A variety of interface languages are available, however most of the indexing is done in either English or Afrikaans. Various searching options are provided, including search according to a single entry or in combination using key words, article title, journal title, abstract, author, author affiliation, volume number, issue number, ISSN, publication month, publication year, accreditation status of the journal, language, and new additions. Client preferences were kept in mind with the design of the search pages - clients can include as little or as much information as needed in the various fields.

A very useful enhancement is the suggestion function in the Journal title field. As soon as a client starts typing a journal title a list of journal title suggestions will appear saving time by making it easy to select a relevant title.

Various browsing options are offered as shown in Figure 2:

An A-Z list of journal titles (already discussed in Scope);

List of subject collections and the list of Open Access journals;

Subscribed titles: individual titles to which clients subscribed can be viewed;

What's new: the latest issues loaded in the past 30 days are displayed which includes the journal titles, issue details, date loaded as well as a link to view the table of contents. A journal's table of contents can also be e-mailed to clients.

General search tips, context-sensitive Help and a Quick Search Guide are also available to streamline searching.

\section{SEARCH ENGINE}

The search interface in Figure 1 reflects most of the search options supported by the search engine. 
FIGURE 3 Search filters

Searches can be conducted according to key words, article title, journal title, abstract, author(s), author affiliation, volume number, issue number, ISSN, publication month, publication year, whether the journal is accredited, accreditation status (i.e., by whom a journal is accredited), language, and new additions. Options for New Additions include: All, today, yesterday, this week, this month, previous month, this year, previous year (2012). Options for language of publication include: All, Afrikaans, Dutch, English, French, German, Italian, Sotho, Spanish, Xhosa, and Zulu. In South African context the search option Only accredited journals is very useful. A date range can be searched (e.g., 2009-2010).

Searches can be done on the full-text, on abstracts, or on both. For searches in the fields for key words and the article title it can be specified that the terms should be an exact phrase (which is important to improve the precision of the search result). By default it does not need to be an exact phrase. The Boolean operators allowed are AND, OR, NOT. It seems from the interface as if this applies between the Keyword field and words appearing in the Title field, as well as by default between the Keyword field and other fields. The default Boolean operator is AND.

The use of a variety of faceted filters greatly enhances the strength of the search engine. (Some search filters are depicted in Figure 3).

Predetermined filters are available for the following: accreditation, database, collection in database - with the default being all collections, journal title, language, key word, author, affiliation, publication year, publication month, and publication year groups. For each filter a dropdown menu is available, as well as an option to view more than what is displayed. Results can be filtered (i.e., limited) by making selections from the predetermined faceted filters. If the selection of a particular filter does not deliver the desired result, it is easy to go back to the original results by merely clicking Clear All Filters. It is also easy to return to the original search and to change or adapt the search strategy. The journal title filter displays titles according to the number of hits per title. Journals with the most hits are thus displayed first. This can give a good indication of journal titles to subscribe to or of journal titles where a researcher can publish for good exposure. Similarly the filter for key words displays key words per number of hits, with the key word with the most hits displaying first. The display of key words can be used to refine results to be more specific or to add search terms and improve recall (i.e., to improve comprehensiveness).

The advanced indexing functionality of Sabinet Reference indexes the full text of the articles available through African Electronic Journals (SA ePublications). It automatically assigns key words according to the number of times certain words appear in an article and also according to the position of those words and it is therefore able to find results most relevant to a search query. The system does not cater to variations of the word, but does make use of the truncated form and will therefore most likely pick up all the relevant results. For example, behaviour that can be spelt behaviour or behavior will find both forms of the word if the client types in the truncated form behav*.

\section{SEARCH RESULTS}

Search results, as depicted in Figure 3 are numbered and appear with a part of the abstract, highlighting the search terms. The full bibliographic detail is displayed. Ten result items are displayed per screen. Results are by default sorted according to relevance, but the sort order can also be changed to sort according to title (ascending and descending) and key words (ascending and descending).

From the search results, items can be marked to be displayed in the Action list from where they can be further managed. (However, finding the Action list on the bottom of the page is somewhat tricky.) From the Action list items can be printed, e-mailed, or exported to a citation manager. The options for the exportation of references are CSV, RefWorks, and EndNote.

The full text of the article can be accessed by clicking on the Adobe reader image. The item details can also be expanded by clicking on the article title. 


\section{African Electronic Journals Review Scores Composite: $\star \star \star \star \star 1 / 4$}

The maximum number of stars in each category is 5 .

Content:

$\star \star \star \star 1 / 2$

African Electronic Journals (SA ePublications) is an authoritative, unique, and high-quality database which covers a wide variety of topics on South African and southern African content with the added advantage that all the articles are available in full text. Although it does not cover all African journals, it still is an essential resource for any researcher from southern Africa and for any research related to southern Africa.

\section{User Interface/Searchability: $\quad \star \star \star \star 1 / 2$}

The interface is user-friendly and offers a variety of options for clients. Sabinet is committed to on-going improvements such as the new user interface. The new interface is very user-friendly and functional towards the novice as well as expert searcher. It supports navigation, searching, and the display of results.

\section{Pricing:}

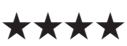

The pricing options are very flexible, reasonable, and definitely in the price range of all South African and international institutions. Clients can (1) subscribe to the full collection of journal titles, (2) choose one or more of the seven subject collections, or (3) subscribe to individual journal titles. An option for non-subscribers to purchase single articles is also available.

\section{Contract Options:}

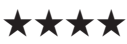

Sabinet is quite flexible in their contract, and the needs of all possible users have been taken into account. The contract is renewable on an annual basis and the process is an uncomplicated one.

Various options for further action are displayed on the right of the results screen. These include linking to related content, displaying all issues of the journal, searching in the journal, or displaying the full record in PDF format. A symbol appears next to each record which indicates whether the journal is accredited. All articles are full-text items and are available in PDF format. The size of the item to be downloaded is also indicated.

\section{OTHER FEATURES}

An alert service adds further value to subscription to African Electronic Journals (SA ePublications). Subscribed clients can receive email alerts of all new issues of journals added to the database, or for alerts on specific journal titles they can subscribe to RSS feeds. These alerts run on a daily basis. Subscribers can also set up alerts according to their own criteria (as they would do a key word search) through the mySabinet functionality. The time of this alert can be specified by the user.

\section{COMPARISON WITH SIMILAR PRODUCTS ON THE MARKET}

African Electronic Journals (SA ePublications) is the only database offering access to full-text articles. Although some of the journal titles are also included in international databases, African Electronic Journals (SA ePublications) is the only one with a clearly demarcated geographic context providing full-text access to its content. Although it does not cover all the journals published in the demarcated region, most of the core journals in a particular subject field are covered. It is the database of choice for librarians and researchers who need information of southern African origin.

\section{Contract Provisions}

Sabinet is quite flexible in their contract, also in considering the needs of their international clients. Subscribers receive a list of all the available journals on an annual basis and they can then indicate whether they are interested in the new title additions. Contract renewal is an easy process.

Sabinet's requirements with regard to subscribing institutions include the following: the need to make the material available on-site and off-site via its secure network; to permit authorised clients to print and/or download individual articles; to allow employees of the institution to make hard copies of the material and distribute and include them in course packs in reasonable amounts; and allowing institutional interlending.

\section{Authentication}

Bibliographic information for all items included in African Electronic Journals (SA ePublications) is available and searchable to anyone; subscription to African Electronic Journals (SA ePublications) or other Sabinet products is not a requirement. Links to the full-text articles available from African Electronic Journals (SA ePublications) is, however, reserved for subscribers via IP Authentication or a user ID and password authentication. Clients can also select to login to certain journals only. Open Access publications are available free of charge with a simple e-mail registration.

\section{Conclusion}

African Electronic Journals (SA ePublications) is a very useful database, providing high quality access to peer-reviewed articles from 


\section{Contact Information}

\section{Sabinet}

P O Box 9785,

Centurion, 0046

South Africa

Phone: +(27) 126439500

Fax: $\quad+(27) 126633543$

E-mail: <info@sabinet.co.za>

URL: <www.sabinet.co.za>

journal publications from a geographically demarcated area, and catering for topics to a broad audience. According to feedback from industry Sabinet's client support is also excellent and problems receive attention immediately. In conclusion it can be said that African Electronic Journals (SA ePublications) is an essential and authoritative resource for any researcher from southern Africa and for any research related to southern Africa.

\section{Author's References}

Ina Du Toit. "From Gold Corporate Partners African electronic journals: Sabinet ePublications," IFLA Journal 38 (2012): 335-37. Accessed February 12, 2013, doi:10.1177/0340035212465144.

\section{About the Authors}

Elsabe Olivier is the recently appointed Assistant Director of Marketing and Quality Assurance of the Department of Library Services at the University of Pretoria. Formerly she was responsible for the Open Scholarship initiatives of the Department, which entailed the management of UPeTD <http://upetd.up.ac.za/UPeTD.htm> (UP's electronic theses and dissertations repository) as well as the collection openUP <http://repository.up.ac.za/handle/2263/121> (Open Access collection of published research articles authored by UP researchers) in the institutional repository UPSPace $<$ http://repository.up.ac.za/ $>$.

Dr Ina Fourie is a full professor in the Department of Information Science, University of Pretoria. Her research on information behaviour, current awareness services and information literacy (amongst other topics) features in national and international contexts. She serves on the editorial advisory board of several ISI listed journals and has been writing a regular column for Library Hi Tech since 2011. 